M-1592

J. Chem. Thermodynamics 1984, 16, 81-90

\title{
Thermophysics of metal alkanoates III. Heat capacities and thermodynamic properties of lithium and potassium propanoates ${ }^{a}$
}

\author{
P. FRANZOSINI ${ }^{b}$ and EDGAR F. WESTRUM, JR. \\ Department of Chemistry, University of Michigan, \\ Ann Arbor, Michigan 48109, U.S.A.
}

(Received 23 May 1983; in revised form 11 July 1983)

\begin{abstract}
At $298.15 \mathrm{~K}$, the values of $C_{p, m} / R, S_{\mathrm{m} /}^{\circ} / R,\left\{H_{\mathrm{m}}^{\circ}-H_{\mathrm{m}}^{\circ}(0)\right\} / R$, and $\left\{G_{\mathrm{m}}^{\circ}-H_{\mathrm{m}}^{\circ}(0)\right\} / R T$ are 15.58 , $17.13,2588.6 \mathrm{~K}$, and -8.445 for $\mathrm{CH}_{3} \mathrm{CH}_{2} \mathrm{CO}_{2} \mathrm{Li}(\mathrm{cr})$, and 17.30, 21.16, 3134.0 K, and -10.647 for $\mathrm{CH}_{3} \mathrm{CH}_{2} \mathrm{CO}_{2} \mathrm{~K}$ (cr). The energetics and shape of the (crystal III-to-crystal II) transition at $T_{\text {trs }}=255 \mathrm{~K}$ in the potassium compound are investigated. The lithium compound showed a (crystal II-to-crystal I) transition not far above $500 \mathrm{~K}$, and fusion at $606.8 \mathrm{~K}$. Relative trends in the $\mathrm{Li}, \mathrm{Na}$, and $\mathrm{K}$ salts are unexplained because of lack of structural information.
\end{abstract}

\section{Introduction}

Previous papers of the present series ${ }^{(1,2)}$ report the thermophysical behavior of the three lowest homologs of the sodium $n$-alkanoate family (methanoate, ethanoate, and propanoate). In order to investigate how changing the cation affects the molar heat capacity within a group of alkali alkanoates having a common anion, propanoates are now preferred to methanoates or ethanoates inasmuch as d.s.c. analysis shows ${ }^{(3)}$ that for both methanoates and ethanoates solid-state transitions (when present) are often very sluggish and, moreover, that there is a tendency to form vitreous phases (e.g. in lithium methanoate and ethanoate). This work concerns mainly the thermophysics of lithium and potassium propanoates from liquid-helium temperatures up to $350 \mathrm{~K}$; some results obtained for the former salt in the superambient region are also included.

For subsequent discussion, it is convenient to summarize (in table 1) the pertinent information available in the literature.

\section{Experimental}

Lithium and potassium propanoates were prepared by reacting in turn Fluka puriss. $\mathrm{Li}_{2} \mathrm{CO}_{3}$ (in de-ionized water) and Fluka puriss. $\mathrm{K}_{2} \mathrm{CO}_{3}$ (in anhydrous methanol)

\footnotetext{
- This research was supported in part by the Structural Chemistry and Chemical Thermodynamics Program of the Division of Chemistry of the National Science Foundation under Grant CHE-8007977. The preceding papers in this series are references 1 and 2.

- Present address: Dipartimento di Chimica-Fisica, University of Pavia, Pavia, Italy.
} 
with a slight excess ( 2 per cent) of Fluka puriss. p.a. $(\geqslant 99.5$ moles per cent; tested by g.c. at the origin) propanoic acid. Solid lithium propanoate was recovered by vacuum freeze-drying, and subsequently purified by dissolution in methanol and fractional precipitation with ethyl ether. Solid potassium propanoate was recovered by evaporation of the solvent and excess acid under reduced pressure in a Rotavapor device at about $330 \mathrm{~K}$, and subsequently purified by recrystallization from (isopropanol + ethanol + methanol) $(4,2,1$ by volume). Both salts were dried after purification under vacuum at about $330 \mathrm{~K}$ to constant mass, and tested by d.s.c., which gave records fully agreeing with those reported in reference 3 . The finely ground portions employed for the preparation of the samples were submitted to final drying at about $400 \mathrm{~K}$ for a few days before use.

The technique of computer-operated equilibrium adiabatic calorimetry in both cryogenic and superambient regions has been described previously. ${ }^{(1)}$ The goldplated copper calorimeter employed with the Mark X cryostat in the temperature range between the liquid-helium region and $350 \mathrm{~K}$ was loaded with $28.0860 \mathrm{~g}$ of $\mathrm{CH}_{3} \mathrm{CH}_{2} \mathrm{CO}_{2} \mathrm{Li}(0.3510 \mathrm{~mol}$, calculated on the basis of the IUPAC 1973 relative atomic masses) and $37.7891 \mathrm{~g}$ of $\mathrm{CH}_{3} \mathrm{CH}_{2} \mathrm{CO}_{2} \mathrm{~K}(0.3369 \mathrm{~mol})$. The silver calorimeter employed with the Mark IX thermostat for the exploratory measurements in the superambient region was loaded with $21.3269 \mathrm{~g}$ of $\mathrm{CH}_{3} \mathrm{CH}_{2} \mathrm{CO}_{2} \mathrm{Li}(0.2665 \mathrm{~mol})$. After loading, the air within the calorimeters was replaced with a few $\mathrm{kPa}$ (at $300 \mathrm{~K}$ ) of helium, and buoyancy corrections were calculated.

\section{Results}

The experimental molar heat capacities obtained in the Mark X cryostat arc listed in chronological order in table 2 and shown in figure 1 for lithium propanoate, and

TABLE 1. Phase changes of lithium and potassium propanoates as reported in previous literature

\begin{tabular}{|c|c|c|c|c|c|}
\hline Salt & Phase change & $T / \mathbf{K}$ & $\Delta H_{\mathrm{m}} /(R \mathrm{~K})$ & Method & Ref. \\
\hline $\mathrm{CH}_{3} \mathrm{CH}_{2} \mathrm{CO}_{2} \mathrm{Li}$ & $\begin{array}{l}\operatorname{trs}^{a} \\
\text { fus } \\
\text { fus } \\
\text { trs } \\
\text { fus }(m)^{c} \\
\text { fus }\end{array}$ & $\begin{array}{l}538 \\
602 \\
600 \pm 1 \\
533 \pm 2 \\
584 \\
606.8\end{array}$ & $\begin{array}{r}- \\
- \\
400 \\
2140 \\
1910\end{array}$ & $\begin{array}{l}\text { visual } \\
\text { visual } \\
\text { d.s.c. } \\
\text { d.s.c. }\end{array}$ & $\begin{array}{l}4 \\
5 \\
6 \\
3\end{array}$ \\
\hline $\mathrm{CH}_{3} \mathrm{CH}_{2} \mathrm{CO}_{2} \mathrm{~K}$ & $\begin{array}{l}\text { trs } \\
\text { trs } \\
\text { fus } \\
\text { fus } \\
\text { fus } \\
\text { trs } \\
\text { trs } \\
\text { fus }\end{array}$ & $\begin{array}{l}341 \\
603 \\
639 \\
628 \\
631 \pm 1 \\
258 \pm 2 \\
352.5 \\
638.3\end{array}$ & $\begin{array}{r}- \\
- \\
- \\
- \\
- \\
40 \\
210 \\
2420\end{array}$ & $\begin{array}{l}\text { visual } \\
\text { visual } \\
\text { micr. } \\
\text { d.s.c. } \\
\text { d.s.c. }\end{array}$ & $\begin{array}{l}4 \\
7 \\
8 \\
6 \\
3^{e}\end{array}$ \\
\hline
\end{tabular}


TABLE 2. Experimental heat capacities of lithium propanoate $\left(\mathrm{CH}_{3} \mathrm{CH}_{2} \mathrm{CO}_{2} \mathrm{Li}\right)$ and potassium propanoate $\left(\mathrm{CH}_{3} \mathrm{CH}_{2} \mathrm{CO}_{2} \mathrm{~K}\right){ }^{4}\left(R=8.3144 \mathrm{~J} \cdot \mathrm{K}^{-1} \cdot \mathrm{mol}^{-1}\right)$

\begin{tabular}{|c|c|c|c|c|c|c|c|c|c|c|}
\hline$T / \mathrm{K} \quad \mathcal{C}_{\mathrm{p}, \mathrm{m}} / R$ & $T / \mathbf{K}$ & $C_{p, m} / R$ & $T / \mathbf{K}$ & $C_{p, \mathrm{~m}} / R$ & $T / K$ & $C_{p, \mathrm{~m}} / R$ & $T / \mathrm{K}$ & $C_{p, \mathrm{~m}} / R$ & $T / \mathbf{K}$ & $C_{\mathrm{p}, \mathrm{m}} / R$ \\
\hline \multicolumn{11}{|c|}{$\begin{array}{c}\text { Lithium propanoate } \\
\text { (Results taken in Mark X cryostat) } \\
\text { Crystal II }\end{array}$} \\
\hline Series I & \multirow{2}{*}{343.90} & 17.613 & \multirow{2}{*}{$\begin{array}{l}159.33 \\
164.43 \\
169.54\end{array}$} & \multirow{2}{*}{$\begin{array}{r}9.811 \\
10.027 \\
10.247\end{array}$} & \multicolumn{2}{|c|}{$236.17 \quad 12.954$} & \multirow{3}{*}{$\begin{array}{l}86.49 \\
90.47 \\
94.47 \\
98.46\end{array}$} & \multirow{3}{*}{$\begin{array}{l}6.108 \\
6.342 \\
6.564 \\
6.780\end{array}$} & \multirow{3}{*}{$\begin{array}{l}21.9 \\
24.0 \\
26.4 \\
32.5\end{array}$} & \multirow{3}{*}{$\begin{array}{l}0.850 \\
1.041 \\
1.265 \\
1.875\end{array}$} \\
\hline 244.3913 .275 & & es II & & & 241.30 & 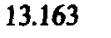 & & & & \\
\hline $\begin{array}{ll}250.88 & 13.560 \\
258.01 & 13.866\end{array}$ & 95.46 & 6.613 & 174.65 & 10.461 & Serie & s II & & & & \\
\hline $265.15 \quad 14.163$ & 99.25 & 6.821 & 179.75 & 10.674 & 237.13 & 12.982 & \multirow{2}{*}{\multicolumn{2}{|c|}{ Series $\mathbf{V}$}} & 35.89 & 2.208 \\
\hline $272.31 \quad 14.448$ & 103.61 & 7.057 & 184.86 & 10.875 & 242.34 & & & & 39.39 & 2.543 \\
\hline $279.47 \quad 14.763$ & 108.63 & 7.332 & 189.98 & 11.098 & 247.53 & 13.403 & 8.48 & $0.060^{b}$ & 42.96 & 2.870 \\
\hline $286.63 \quad 15.075$ & 113.65 & 7.596 & 195.11 & 11.304 & 252.67 & 13.629 & 9.11 & 0.1 & 46.60 & 3.194 \\
\hline 293.8015 .391 & 118.69 & 7.865 & 200.24 & 11.519 & & & 10.01 & $0.103^{b}$ & 50.29 & 3.511 \\
\hline $300.96 \quad 15.698$ & 123.73 & 8.124 & 205.37 & 11.719 & Serie & s & 10.91 & $0.246^{b}$ & 54.54 & 3.857 \\
\hline $308.11 \quad 16.020$ & 128.82 & 8.379 & 210.51 & 11.921 & 63.80 & 4.584 & 12.06 & 0.178 & 59.07 & 4.216 \\
\hline 2616.346 & 133.91 & 8.637 & 215.64 & 12.136 & 66.96 & 4.8 & 14.52 & 0.3 & 63.36 & 4.5 \\
\hline 216.66 & 138.98 & 8.88 & 220.77 & 12.3 & 71.10 & & 15.65 & 0.3 & & 4.8 \\
\hline 716.995 & 114.05 & 9.128 & 225.90 & 12.535 & 74.92 & 5.335 & 16.90 & 0.447 & 71.91 & 5.138 \\
\hline $336.74 \quad 17.290$ & 149.13 & 9.360 & 231.03 & 12.746 & 78.55 & 5.5 & 18.31 & 0.548 & & \\
\hline & .24 & 9.586 & & & 82.52 & 5.850 & 20.07 & 0.686 & & \\
\hline
\end{tabular}

(Results taken in Mark IX thermostat)

Crystal II

Series I

310.0816 .241

317.4116 .658

324.5516 .897

Series I

530.8521 .291

331.7716 .959

340.4317 .639

350.6117 .968

$360.84 \quad 18.402$

371.0718 .759

381.3719 .129

392.7419 .467

403.0319 .711

413.3219 .954 423.6320 .135

433.9420 .351

444.2620 .525

$454.50 \quad 20.642$ 464.6220 .844

474.7420 .983

484.8621 .164

\section{Crystal I}

540.7821 .413 551.1021 .709 $\begin{array}{llll}561.42 & 21.943 & 582.05 & 22.515\end{array}$
494.9721 .352

505.0721 .544

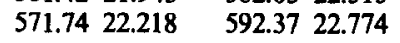

Potassium propanoate

(Results taken in Mark X cryostat)

\section{Crystal III}

\begin{tabular}{|c|c|}
\multicolumn{2}{c}{ Series II } \\
\hline 170.80 & 12.151 \\
175.66 & 12.354 \\
181.81 & 12.618 \\
187.95 & 12.877 \\
194.10 & 13.130 \\
200.29 & 13.400 \\
206.48 & 13.677 \\
212.60 & 13.951 \\
218.73 & 14.237 \\
224.88 & 14.532 \\
231.03 & 14.825 \\
237.17 & 15.141
\end{tabular}

$\begin{array}{cc}243.31 & 15.470 \\ 247.90 & 15.700 \\ \text { Series III } \\ 103.97 & 9.053 \\ 108.29 & 9.280 \\ 113.35 & 9.558 \\ 118.43 & 9.833 \\ 123.50 & 10.074 \\ 128.49 & 10.326 \\ 133.53 & 10.559 \\ 138.62 & 10.786 \\ 143.72 & 11.012\end{array}$

\begin{tabular}{|c|c|c|c|}
\hline & & & \multirow[b]{2}{*}{0.107} \\
\hline \multirow[b]{2}{*}{102} & 7.024 & 9.16 & \\
\hline & 7.308 & 10.19 & 0.145 \\
\hline 81.53 & 7.609 & 11.35 & 0.196 \\
\hline 85.51 & 7.922 & 12.65 & 0.268 \\
\hline 89.51 & 8.194 & 14.11 & 0.362 \\
\hline 93.53 & 8.436 & 15.89 & 0.501 \\
\hline 97.56 & 8.673 & 17.79 & 0.665 \\
\hline 101.60 & 8.908 & 19.73 & 0.851 \\
\hline 105.65 & 9.136 & 21.95 & 1.084 \\
\hline \multirow{2}{*}{\multicolumn{2}{|c|}{ Series V }} & 24.43 & 1.363 \\
\hline & & 27.18 & 1.691 \\
\hline 7.5 & $0.055^{b}$ & 29.04 & 1.922 \\
\hline & & 32.16 & 2.320 \\
\hline
\end{tabular}

$\begin{array}{ll}35.29 & 2.731 \\ 38.75 & 3.179 \\ 42.50 & 3.653 \\ 46.66 & 4.180 \\ 51.13 & 4.708 \\ 55.71 & 5.225 \\ 60.37 & 5.727 \\ 65.08 & 6.206\end{array}$

Series VI $237.4815 .168^{c}$ 
TABLE 2-continued

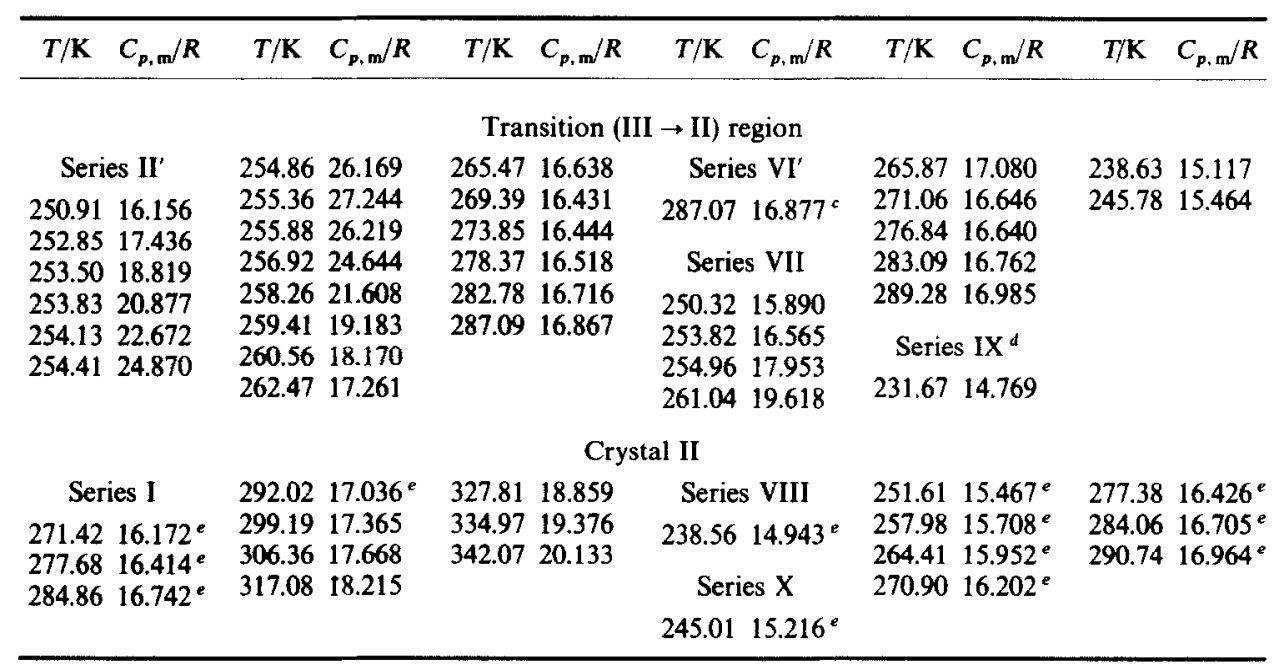

" In chronological sequence by series, i.e. with increasing Roman numbers (I, II, II', II", III, etc.) and within each series.

${ }^{b}$ Not included in curve fit because of deviation from smooth curve.

' Not employed for curve fit.

- Crystal II partially converted into crystal III.

${ }^{\circ}$ Crystal II in a metastable (undercooled) state.

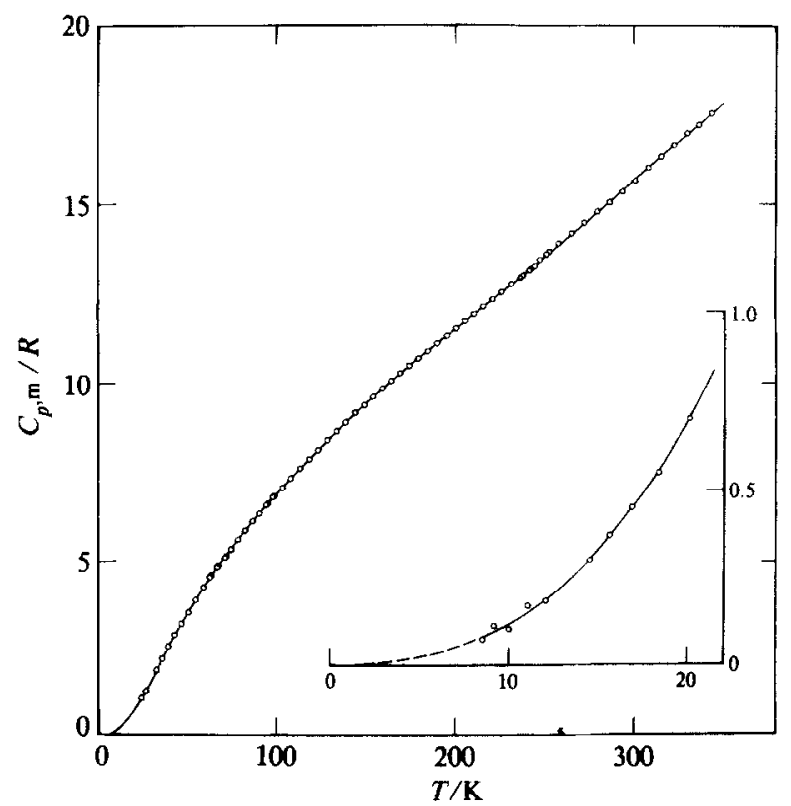

FIGURE 1. Heat capacities of lithium propanoate taken in the Mark X cryostat below $350 \mathrm{~K}$. 


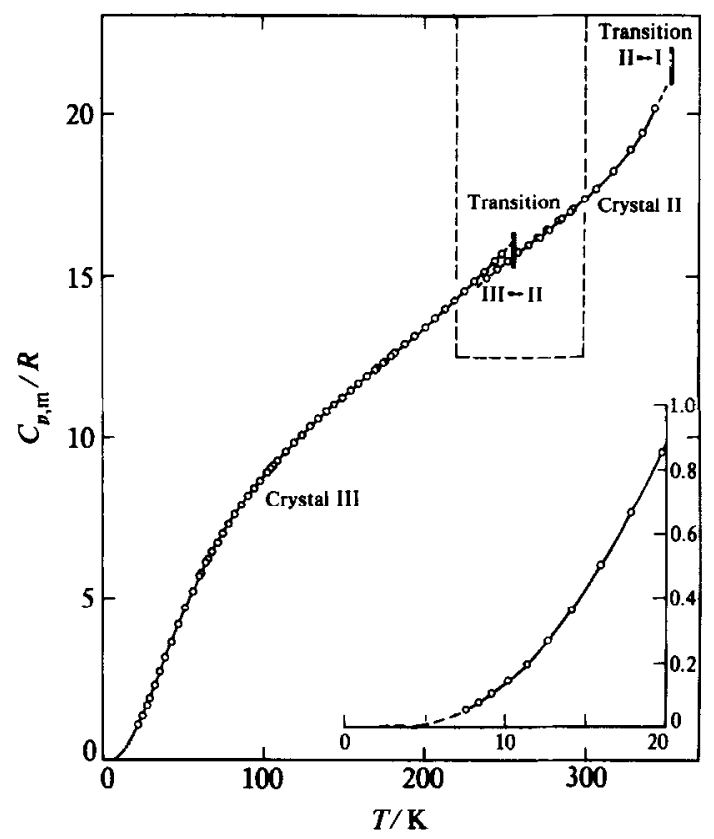

FIGURE 2. Heat capacities of potassium propanoate taken in the Mark X cryostat below $350 \mathrm{~K}$. The interval between 220 and about $300 \mathrm{~K}$ (which includes the III $\rightarrow$ II transition region) is magnified in figure 3.

in figures 2 and 3 for potassium propanoate. For a set of selected temperatures, smoothed $C_{p, m} / R$ values and the derived thermodynamic functions were calculated as described in reference 1 and are listed in table 3.

The molar heat capacities obtained in the Mark IX thermostat for lithium propanoate are tabulated also in table 2 and shown in figure 4.

\section{POTASSIUM PROPANOATE CRYSTALLINE PHASES II AND III}

D.s.c. allowed one of $\mathrm{us}^{(3)}$ to obtain evidence for the following phase relations in potassium propanoate:

$$
\text { crystal III } \underset{(258 \pm 2) \mathrm{K}}{\stackrel{T_{\mathrm{IU} \rightarrow \mathrm{N}}}{=}} \text { crystal II } \underset{352.5 \mathrm{~K}}{\stackrel{T_{\mathrm{U}-1}}{=}} \text { crystal I } \underset{638.3 \mathrm{~K}}{\stackrel{T_{\text {Im }}}{=}} \text { liquid. }
$$

Massarotti and Spinolo ${ }^{(10)}$ claimed on the basis of powder X-ray diffractometry that crystal I is orthorhombic and crystal II monoclinic, and that the latter exists in a metastable (undercooled) state to about $30 \mathrm{~K}$ below $T_{\text {III } \rightarrow \text { II }}$. Moreover, the structural differences between crystal III and crystal II-unambiguously proved by the recorded patterns-were so remarkable (although the indexing procedure was unsuccessful with crystal III) that a "true" (first-order) phase change is probably involved in the (III $\rightarrow$ II) transformation. However, the present calorimetric results (compare figure 3) show that the transition is not isothermal. 


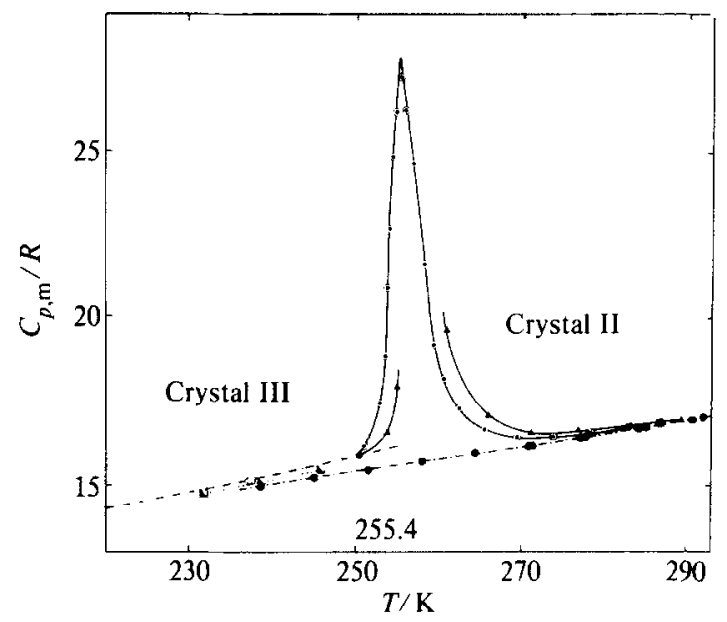

FIGURE 3. Heat capacities of potassium propanoate taken in the Mark $X$ cryostat through the III $\rightarrow$ II transition region. For further explanation see text.

The possibility that crystalline solids might undergo gradual phase transitions has been discussed by Allen and Eagles. ${ }^{(1)}$ Their arguments were adopted, e.g. by Oetting and McDonald ${ }^{(12)}$ to classify the $(\alpha \rightarrow \beta)$ transition of magnesium pyrophosphate as first-order, and it is to be stressed that the heat-capacity curve of this salt has features in the $(\alpha \rightarrow \beta)$ transition region quite similar to those observed in the (III $\rightarrow$ II) transformation range of potassium propanoate.

Massarotti and Spinolo's ${ }^{(10)}$ results as well as the shape of the heat-capacity curve suggest-even in the absence of supplementary information, e.g. on the pertinent volume change - that the $\mathrm{CH}_{3} \mathrm{CH}_{2} \mathrm{CO}_{2} \mathrm{~K}$ (III $\rightarrow$ II) transition is of first rather than

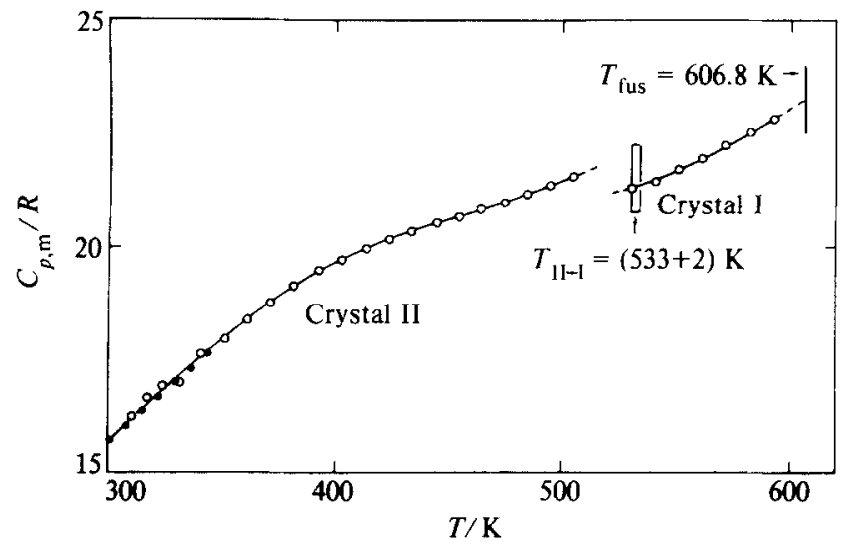

FIGURE 4. Heat capacities of lithium propanoate taken between $300 \mathrm{~K}$ and the melting temperature: $O$, in the Mark $X$ cryostat, and $O$, in the Mark IX thermostat. The melting temperature and transition temperature are d.s.c. results from reference 3. 
TABLE 3. Molar thermodynamic functions of propanoates $\left(R=8.3144 \mathrm{~J} \cdot \mathrm{K}^{-1} \cdot \mathrm{mol}^{-1}\right)$

\begin{tabular}{|c|c|c|c|c|}
\hline$\frac{T}{\mathbf{K}}$ & $\frac{C_{p, m}}{R}$ & $\frac{S_{m}^{o}(T)-S_{m}^{\circ}(0)}{R}$ & $\frac{H_{\mathrm{m}}^{\circ}(T)-H_{\mathrm{m}}^{\circ}(0)}{R \mathbf{K}}$ & $-\frac{G_{\mathrm{m}}^{\circ}(T)-H_{\mathrm{m}}^{\circ}(0)}{R T}$ \\
\hline \multicolumn{5}{|c|}{ Lithium propanoate } \\
\hline \multicolumn{5}{|c|}{ Crystal II } \\
\hline 0 & 0.0 & 0.0 & 0.0 & 0.0 \\
\hline 10 & 0.102 & 0.033 & 0.251 & 0.008 \\
\hline 15 & 0.327 & 0.113 & 1.268 & 0.028 \\
\hline 20 & 0.681 & 0.252 & 3.740 & 0.065 \\
\hline 25 & 1.128 & 0.451 & 8.231 & 0.122 \\
\hline 30 & 1.621 & 0.700 & 15.094 & 0.197 \\
\hline 40 & 2.600 & 1.302 & 36.269 & 0.396 \\
\hline 50 & 3.487 & 1.979 & 66.76 & 0.644 \\
\hline 60 & 4.292 & 2.688 & 105.75 & 0.925 \\
\hline 70 & 5.012 & 3.404 & 152.33 & 1.228 \\
\hline 80 & 5.672 & 4.117 & 205.80 & 1.545 \\
\hline 90 & 6.287 & 4.821 & 265.62 & 1.870 \\
\hline 100 & 6.865 & 5.514 & 331.41 & 2.200 \\
\hline 120 & 7.939 & 6.862 & 479.63 & 2.865 \\
\hline 140 & 8.924 & 8.161 & 648.4 & 3.529 \\
\hline 160 & 9.836 & 9.413 & 836.1 & 4.187 \\
\hline 180 & 10.689 & 10.621 & 1041.4 & 4.835 \\
\hline 200 & 11.504 & 11.790 & 1263.4 & 5.473 \\
\hline 220 & 12.302 & 12.924 & 1501.5 & 6.099 \\
\hline 240 & 13.105 & 14.028 & 1755.5 & 6.714 \\
\hline 260 & 13.932 & 15.11 & 2025.9 & 7.318 \\
\hline 280 & 14.788 & 16.17 & 2313.0 & 7.913 \\
\hline 298.15 & 15.58 & 17.13 & 2588.6 & 8.445 \\
\hline 300 & 15.67 & 17.22 & 2617.5 & 8.498 \\
\hline 320 & 16.55 & 18.26 & 2939.7 & 9.076 \\
\hline 350 & 17.97 & 19.81 & 3457.3 & 9.930 \\
\hline 400 & 19.64 & 22.33 & 4400.9 & 11.323 \\
\hline 450 & 20.60 & 24.70 & 5409 & 12.679 \\
\hline 500 & 21.44 & 26.91 & 6459 & 13.993 \\
\hline 514 & $(21.75)^{a}$ & (27.51) & (6761) & $(14.353)$ \\
\hline \multicolumn{5}{|c|}{ Crystal I } \\
\hline 514 & $(21.17)^{a}$ & (28.33) & (7186) & $(14.353)$ \\
\hline 550 & 21.65 & 29.78 & 7954 & 15.32 \\
\hline 600 & 22.94 & 31.72 & 9070 & 16.60 \\
\hline \multicolumn{5}{|c|}{ Potassium propanoate } \\
\hline \multicolumn{5}{|c|}{ Crystal III } \\
\hline 0 & 0.0 & 0.0 & 0.0 & 0.0 \\
\hline 10 & 0.135 & 0.046 & 0.341 & 0.012 \\
\hline 15 & 0.430 & 0.150 & 1.679 & 0.038 \\
\hline 20 & 0.877 & 0.332 & 4.891 & 0.087 \\
\hline 25 & 1.429 & 0.585 & 10.620 & 0.161 \\
\hline 30 & 2.044 & 0.900 & 19.284 & 0.257 \\
\hline 40 & 3.339 & 1.665 & 46.190 & 0.510 \\
\hline 50 & 4.577 & 2.545 & 85.85 & 0.828 \\
\hline 60 & 5.690 & 3.480 & 137.31 & 1.191 \\
\hline 70 & 6.655 & 4.431 & 199.16 & 1.586 \\
\hline 80 & 7.482 & 5.375 & 269.95 & 2.001 \\
\hline 90 & 8.195 & 6.299 & 348.42 & 2.427 \\
\hline
\end{tabular}


TABLE 3-continued

\begin{tabular}{ccccc}
\hline \multicolumn{1}{c}{$\frac{T}{\mathbf{K}}$} & $\frac{C_{p, \mathrm{~m}}}{R}$ & $\frac{S_{\mathrm{m}}^{\circ}(T)-S_{\mathrm{m}}^{\circ}(0)}{R}$ & $\frac{H_{\mathrm{m}}^{\circ}(T)-H_{\mathrm{m}}^{\circ}(0)}{R \mathrm{~K}}$ & $-\frac{G_{\mathrm{m}}^{\circ}(T)-H_{\mathrm{m}}^{\circ}(0)}{R T}$ \\
\hline 100 & 8.821 & 7.195 & 433.56 & 2.860 \\
120 & 9.902 & 8.902 & 621.1 & 3.726 \\
140 & 10.849 & 10.501 & 828.8 & 4.581 \\
160 & 11.716 & 12.007 & 1054.5 & 5.416 \\
180 & 12.543 & 13.434 & 1297.2 & 6.228 \\
200 & 13.384 & 14.799 & 1556.3 & 7.017 \\
220 & 14.296 & 16.12 & 1833.0 & 7.785 \\
240 & 15.29 & 17.40 & 2128.8 & 8.533 \\
255 & $(16.10)^{\circ}$ & $(18.35)$ & $(2364.1)$ & $(9.082)$ \\
& & & & \\
255 & $(15.60)^{a}$ & $(18.60)$ & $(2425.7)$ & $(9.083)$ \\
260 & 15.78 & 18.90 & 2504.2 & 9.269 \\
280 & 16.53 & 20.10 & 2827.1 & 9.999 \\
298.15 & 17.30 & 21.16 & 3134.0 & 10.647 \\
300 & 17.39 & 21.27 & 3166.1 & 10.712 \\
320 & 18.37 & 22.42 & 3523.4 & 11.408 \\
340 & 19.89 & 23.57 & 3904.2 & 12.089 \\
\hline
\end{tabular}

"At this transition temperature the values of the heat capacities are the extrapolated "lattice" values; the other thermodynamic properties are predicted on a presumably isothermal transition.

of higher order. The thermodynamic functions listed in table 3 were, therefore, calculated accordingly.

The temperature interval between 220 and about $300 \mathrm{~K}$, which includes the (III $\rightarrow$ II) transition region, is magnified in figure 3 . In order to fit polynomial 1 by least-squares through the experimental results taken on crystal II the points belonging to Series I, VIII, and $X$ were employed (in figure 3 these points are represented by filled circles). Polynomial 2 was fitted through the results taken on crystal III, employing the points belonging to Series III, IV, and V along with those of Series II up to $243.31 \mathrm{~K}$ (in figure 3 these points are represented by open circles). In Series II, the point at $247.90 \mathrm{~K}$ (represented by an open square) still falls on the curve pertinent to polynomial 2, but the next (at $250.91 \mathrm{~K}$ ) and the following ones (tabulated as Series II', and represented by circled dots) depart from it, going through a maximum $\left(T_{\max }=255.4 \mathrm{~K}\right.$ ) and finally joining polynomial 1 . (In figure 3 , the empty and filled squares represent heat capacities-belonging to different Series-relevant to crystal III and crystal II, which were not utilized for curve fitting.) The "transition region" thus apparently covers the interval between 249 and $293 \mathrm{~K}$ : consequently, results taken on crystal II below the latter temperature are to be attributed to a metastable (undercooled) state of this polymorph.

The area (in figure 3) whose upper boundary is the curve drawn through the circled dots and whose lower boundary is represented by the curve of polynomial 1 (-. - ) from 293 down to $255.4 \mathrm{~K}$, the extrapolated curve of polynomial $2\left(-\right.$ - $\left.^{-}\right)$ from 249 up to $255.4 \mathrm{~K}$, and a short vertical segment connecting the two curves at the latter temperature, was integrated graphically, and gave $\Delta_{\mathrm{trs}} H_{\mathrm{m}} / R=62.3 \mathrm{~K}$. The rounded values $T_{1 \mathrm{II} \rightarrow \mathrm{II}}=(255 \pm 1) \mathrm{K}$ and $\Delta_{\mathrm{trs}} H_{\mathrm{m}} / R=(62 \pm 1) \mathrm{K}$ can be assumed as the (III $\rightarrow$ II) transition temperature and enthalpy increment. The previous d.s.c. 
values: $:^{(3)}(258 \pm 2) \mathrm{K}$ and $40 \mathrm{~K}$, respectively, can be favorably compared with them, although the agreement is not very close for the enthalpy increment.

It is to be stressed that the location of the transition is to some extent affected by the thermal history of the sample, in the sense that, after repeated cooling cycles, $T_{\text {trs }}$ was found to be somewhat displaced towards the higher temperatures, as is apparent when the points of Series $\mathrm{II}^{\prime}$ (circled dots in figure 3) are compared with those of Series VII (triangles). We recommend the $T_{\text {irs }}$ value determined after the first deep cooling of the sample, i.e. $(255 \pm 1) \mathrm{K}$, as the correct one. In contrast, thermal history seems to have a minor influence on the heat capacities of the two phases involved.

In agreement with the findings by Massarotti and Spinolo, ${ }^{(10)}$ crystal II could be undercooled to about $235 \mathrm{~K}$ (compare Series VIII); cooling to about $230 \mathrm{~K}$ allowed us to observe a partial conversion to phase III (compare Series IX, whose pointsrepresented by half-filled squares in figure 3-are intermediate between the curves of polynomials 1 and 2). Cooling to lower temperatures caused complete conversion to occur more quickly.

\section{LITHIUM PROPANOATE IN THE SUPERAMBIENT REGION}

Only one series of measurements was made in this region with the Mark IX thermostat; the silver calorimeter cracked during the first freezing of the molten salt. This prevented checking of the reproducibility of the heat capacities after fusion and subsequent cooling of the sample, and also the investigation of the (II $\rightarrow$ I) transition and melting processes. The $C_{p, m} / R$ values taken on crystal II (in the upper part of its field of existence) and on crystal $I$ are thus to be considered as exploratory, but nevertheless worthy of publication due to the (so far complete) lack of equilibrium values. The results are plotted in figure 4 along with the points taken at $T>300 \mathrm{~K}$ with the Mark X cryostat.

The agreement was satisfactory with the fusion temperature $\left(T_{\text {fus }}=606.8 \mathrm{~K}\right)$ obtained from d.s.c. records, ${ }^{(3)}$ while the transition $(\mathrm{II} \rightarrow \mathrm{I})$ was observed at a temperature $T_{\mathrm{II} \rightarrow \mathrm{I}}=(514 \pm 2) \mathrm{K}$ remarkably lower than that, $(533 \pm 2) \mathrm{K}$, tabulated in reference 3 . There is, however, no real discrepancy between the two findings, inasmuch as d.s.c. analysis allowed the authors ${ }^{(3)}$ to state that a powdered samplelike that employed in the present work-undergoes transition at a temperature at least $12 \mathrm{~K}$ lower than a previously melted sample-like that to which the $T_{n \rightarrow 1}$ value tabulated in reference 3 actually refers. For the residual difference (about $7 \mathrm{~K}$ ) allowance must be made for some sluggishness still exhibited by solid-state transitions of the propanoates, and for the fact that d.s.c. is a dynamic method of investigation.

\section{COMPARISON AMONG LITHIUM, SODIUM, AND POTASSIUM PROPANOATES BELOW $300 \mathrm{~K}$}

The smoothed heat-capacity curves obtained for the three propanoates in the temperature range between the helium region and $273 \mathrm{~K}$ are compared in figure 5 . At any given temperature, the heat capacity of potassium propanoate remains, as expected, larger than that of the sodium and lithium salts, whereas the $C_{p, m} / R$ curves for $\mathrm{CH}_{3} \mathrm{CH}_{2} \mathrm{CO}_{2} \mathrm{Na}$ and $\mathrm{CH}_{3} \mathrm{CH}_{2} \mathrm{CO}_{2} \mathrm{Li}$ cross at approximately $55 \mathrm{~K}$. The 


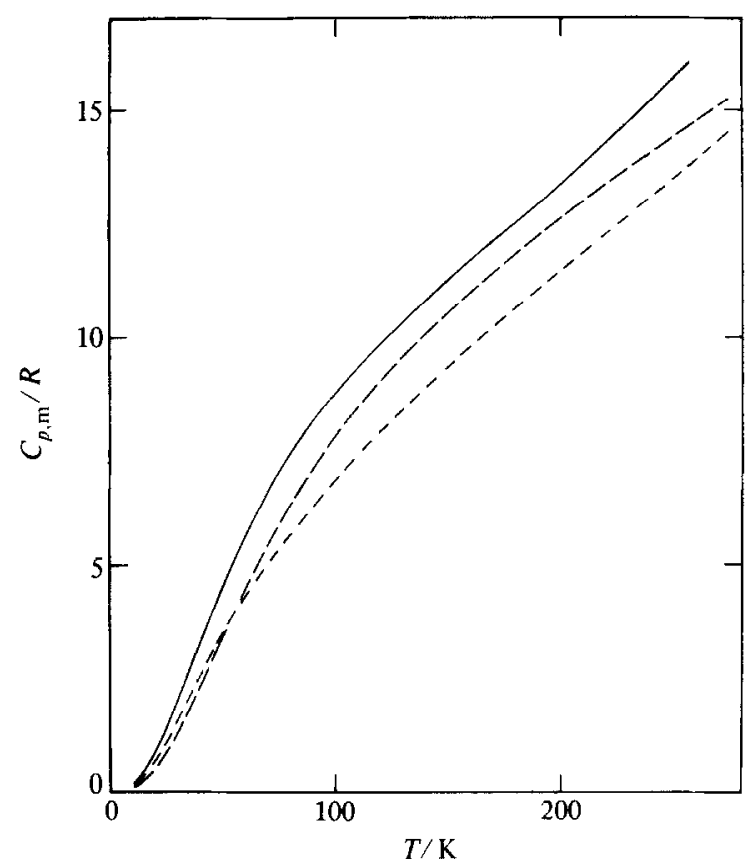

FIGURE 5. Comparison of $C_{p, m} / R$ taken in the low-temperature region for propanoates: - - lithium; - - sodium; - potassium.

reason for this peculiarity is so far not explained because structural information on lithium propanoate is not yet available.

We appreciate the assistance of William A. Plautz in devising computer programs and evaluation schemes to enhance the reliability of these experimental determinations and the resultant evaluated results. One of us (P.F.) gratefully acknowledges the financial support received by the National Science Foundation (U.S.A.) and by the Centro di Studio per la Termodinamica ed Elettrochimica dei Sistemi Salini Fusi e Solidi del C.N.R., Pavia (Italy).

\section{REFERENCES}

I. Franzosini, P.; Plautz, W. A.; Westrum, E. F., Jr. J. Chem. Thermodynamics 1983, 15, 445.

2. Franzosini, P.; Westrum, E. F., Jr.; Plautz, W. A. J. Chem. Thermodynamics 1983, 15, 609.

3. Ferloni, P.; Sanesi, M.; Franzosini, P. Z. Naturforsch. 1975, 30a, 1447.

4. Sokolov, N. M. Summaries of Papers Presented at the 10th Scientific Conference of the Smolensk Medical Institute, 1956. (This reference could not be consulted: it is, however, quoted as the pertinent primary source of information in subsequent papers from the same laboratory.)

5. Tsindrik, N. M.; Sokolov, N. M. J. Gen. Chem. USSR 1958, 28, 1462.

6. Michels, H. J.; Ubbelohde, A. R. J. Chem. Soc. Perkin II 1972, 1879.

7. Sokolov, N. M.; Minich, M. A. Russ. J. Inorg. Chem. 1961, 6, 1293.

8. Baum, E.; Demus, D.; Sackmann, H. Wiss. Z. Univ. Halle 1970, XIX, 37.

9. Cingolani, A.; Spinolo, G.; Sanesi, M. Z. Naturforsch. 1979, 34a, 575.

10. Massarotti, V.; Spinolo, G. J. Appl. Cryst. 1980, 13, 622.

11. Allen, J. W.; Eagles, D. M. Physica 1960, 26, 492.

12. Oetting, F. L.; McDonald, R. A. J. Phys. Chem. 1963, 67, 2737. 